\title{
Credibility Perception of TV News and Debate Shows Before and During Election Campaign
}

\author{
Abdul Muneer $\mathrm{V}^{1}$, Dr. Syed Amjed Ahmed ${ }^{2}$ \\ ${ }^{1}$ (Assistant professor of Journalism, EMEA College of Arts and Science, Kondotti, Kerala, India) \\ ${ }^{21}$ Former Director of EMMRC and Head, Dept of Journalism and Mass Communication, University of Calicut, \\ Kerala, India)
}

\begin{abstract}
Media credibility is known to be situational. When media report and debate major events of national importance, audiences' credibility perceptions about the media are known undergo a change either in the positive or negative direction. Elections to legislative bodies are of great importance to democratic societies. And when the election schedule gets announced, news and debate programmes of television news channels become election- centric. What credibility do the audience attach to these programmes? In an attempt to answer this question, the present study assessed the credibility of news and debate shows telecast by Malayalam news channels before and during election campaigns, and examined whether the credibility of news and debate shows telecast during election campaigns was independent of voters' socio-demographic variables. The results showed that the news and debate shows telecast before the beginning of election campaign had a lower mean credibility as compared to a higher mean credibility during the campaign period. Further, the higher credibility attached to poll news and debate shows telecast during election campaigns was found to be independent of viewers' gender, age, and economic status. But viewer's educational attainment and occupation had a bearing on their credibility assessments. These results unfailingly indicate that media credibility is situational. That news and debate programmes telecast during the election campaign period by Malayalam news channels were perceived to be relatively more credible highlights the importance of such programmes during elections.
\end{abstract}

Keywords: Credibility perception, Election campaign, Media credibility, Television debates, Television news

\section{Introduction}

Election times bring about a substantial change in the newscasts and debate shows of Indian television news channels. Election campaign topics, controversies involving rival political parties and candidates, campaign of celebrity contestants, party manifestoes, public opinion, views of political pundits and other election related aspects dominate the news and debate programmes of news channels. The newscasts, notwithstanding the slants inherent in them provide an account of the latest developments on the election front. The debate shows involving party representatives, political experts and journalists, present an absorbing fare for the television viewers especially to those sensitive to electoral politics. Such programming practices of news channels are known to activate the indifferent voters, reinforce the predispositions of the partisan and convert the predispositions of a few voters. These effects of the media on voting behaviour that were first detected by Lazarsfeld and his colleagues (1944) during the 1940 US presidential election, and later affirmed by scores of other scholars in subsequent decades, stem from the fact that audience are active and selective in attending to information provided by the media. From an active audience perspective, the influence of mass media on their audience would depend on scores of media and audience variables. Of these, the influence would depend on the extent to which the viewers consider such telecasts as credible and trustworthy (Kraus and Davis, 1976). If the audiences do not perceive the media to be credible, then the very assumption of media influencing the voting behavior would be untenable. As Wanta and Hu (1994) have explained, it is the credibility of media that first leads to reliance and exposure of audience to media messages and then leads to the manifestations of effects on the thoughts and behaviour of the audience. Therefore, the credibility dimension of televisions news debate shows deserves to be investigated in studies dealing with mass media and voting behaviour. In this context, the present study was undertaken to explore the credibility aspects of news and debate shows of Malayalam news channels.

\section{I.1 Media Credibility}

The concept of credibility owes it origin to Greek philosopher Aristotle. In his thesis on persuasion, Aristotle described credibility as 'ethos', the Greek expression for 'character' which refers to trustworthiness of source, a requisite for persuasion. Though there is no universally accepted definition, communication scholars define it in similar terms. For O'Keefe (1990 pp. 130-131), credibility is a "judgment made by a perceiver (e.g. a message recipient) concerning the believability of a communicator." According to Bracken (2006), source 
credibility is the amount of believability attributed to a source of information by the receivers. From the above definitions, credibility in simple terms can be defined as receivers' perceptions about source's quality of being credible or believable. In other words, credibility is the believability of a source as perceived by the recipients of the messages.

Credibility is a multidimensional concept. For Aristotle, credibility was made up of three dimensions: intelligence, character, and goodwill. Modern day scholars too have conceived credibility to be a multidimensional construct. For instance, in 1948, Haiman in his classic study of the effect of credibility on persuasion conceived source credibility as being composed of the dimensions of reputation and competence. Yale University psychologists Hovland and his associates Janis and Kelley (1953) in their investigation of WW II communications suggested three components of credibility: expertise, trustworthiness and intention. Following this tradition, a large number of studies focussed on individuals as sources in the context of groups and public speaking. Since 1960s researchers have been conducting studies to understand how media audience perceive credibility of different media such as newspapers, radio, television and internet in recent years (e.g. Sargent, 1965; Newhagen \& Nass, 1989), and how best media credibility components could be grouped under meaningful categories.

In that genre, Gaziano and McGrath's (1986) study remains important. Their study identified as many as 12 components of media credibility in the US. Meyer (1988) grouped Gaziano-McGrath's 12 components into two sets. While one set of seven components represented media affiliation with the community, the other set representing media credibility had five components: accuracy, fairness, trustworthiness, bias and completeness. Meyer's media credibility set has been found to have a strong reliability and validity in measuring media credibility of the media as has been used demonstrated in subsequent studies (Johnson and Kaye, 1998, 2000, Bucy, 2003). Meyer (1988) also showed evidence that newspaper's credibility and believability are be the same dimensions.

The credibility perceptions of media depend on a host of factors. Rimmer and Weaver (1987) have noted that the more the audience uses a particular medium, the more likely they would deem the medium credible. In other words, those who use a particular media more often tend to perceive the credibility of that particular media more positively than those who use it less often. In the same vein, Severin and Tankard, (2001) have argued that credibility often depends on the user's preference and the use of the medium. Kiouis, (2001) and Johnson \& Kaye, (2002) have detected a strong link between the daily use of a medium and its credibility. Bucy (2003) has asserted that those who watched a television channel more frequently tended to evaluate it more favourably than the channels they were not exposed to. Some other studies designed to assess media's role in the formation of political attitudes have related credibility to other factors including TV viewing habits (e.g., Lu and Andrews, 2006). A general trend is that media audiences rate their primary source of news as a credible source. When there is information overload as it normally happens during election periods, media credibility becomes an important heuristic for content (Schweiger, 2000). In most situations and cases, TV happens to be relatively more credible than other media (Geary, 2005).

Further, studies have also shown that credibility perceptions of media do not remain constant across time. Several scholars (Berlo, Lemert, \& Mertz, 1969; Chaffee, 1982) have argued that credibility is highly situational and is subject to change as it is an audience-centric perception. Changes in the media scenario, changes in the media practices, and major events that are of great importance to societies such as elections and other catastrophic events are known to bring about changes in the credibility perception of the media. For example, the increasing popularity of television changed the US media scenario. As a result, television replaced newspapers as the most believable medium as early as 1961 (Roper, 1967) and by 1968 television news had attained confidence from twice as many people as newspapers (Erskine, 1970). Such a high confidence in television however took an unexpected nosedive in 1980s onwards. According to Pew Research Centre for People \& the Press (2002), the believability of the daily newspapers fell by a quarter, from 80 percent in 1985 to 59 percent in 2002. The credibility of three television networks which was above 80 percent in 1985 plunged to lower levels in 2002: 76 percent for CNN, 73 percent for MSNBC and 67 percent for Fox News. Such a decline in credibility of US television networks appears to continue. What were the reasons for such a decline in trust in television and other media? One reason relates to media practices. As Doherty (2005) points out, one of the reasons could be the doubt of many Americans in the news media's fairness in reporting. In short, when fair practices are sidelined media credibility dips. This happened in Britain in 2011 when the Chief Executive of News International, Rebekha Brooks, stepped down after the allegations that her colleagues followed the unethical journalistic practice of hacking into the phone accounts of murder victims and their families. A YouGov survey conducted in Oct 2011 suggested that the phone-hacking scandal resulted in a deep level of mistrust in UK public with as many as 51 percent respondents reporting that their trust has reduced in the UK media as a whole (Thomson, 2011). 
Situational changes such as the occurrence of major events would also bring about changes in the credibility perception of the media. To illustrate this point, Sept 11, 2001 terrorist attack on the US serves as a good example. The deadly attacks on the World Trade Centre (WTC) and Pentagon increased the dependence of Americans on television as it provided breathtaking visual account of the plane crashing into WTC towers, the ensuing inferno and the loss of life. Such coverage of 9/11 boosted news media's image (Nacos, Bloch-Elkon and Shapiro, 2007). A large majority of those who followed these stories rated media coverage of terrorism as excellent or good. Such positive ratings were short lived. They dipped in the following months (Pew Research Centre for People \& the Press, 2002).

Several scholars have pointed to the important influence of audience variables in their assessments of the source and media credibility. These include, variables such as education (Mulder, 1981), gender (Robinson \& Kohut, 1988), income (Ibelema \& Powell, 2001), age (Bucy, 2003), and race (Beaudoin \& Thorson, 2005).

From the above studies it emerges that (i) television is one of the most credible medium for most people everywhere including India if one goes by the fact that more than half of Indian households have a television set and even illiterate watch television news to be abreast of the day-to-day happenings; (ii) those who use television regularly are more likely to perceive it to be more credible than other media; and (iii) credibility is highly situational and is subject to change when social situation changes and the changes could be in the positive or negative directions.

\section{Study Objectives}

Would changes in the coverage of major events that are of great importance to societies such as election to legislative assemblies and parliament bring about changes in the credibility perception of Indian television news channels? An answer to this question cannot be located in the findings of the studies conducted in the Western democracies, especially the US. Instead, answer must come from studies conducted in India. But, credibility studies of Indian media and their content are non-existing.

Against this backdrop, this was conceived to (i) assess the credibility of news and debate shows telecast by Malayalam news channels before and during the election campaigns, and (ii) examine whether the credibility of news and debate shows telecast during election campaigns is independent of voters' socio-demographic variables.

\section{Research Design and Methodology}

The data for the present study was drawn from a larger study conducted by the first author to explore the influence of television news and debates on the voting behaviour of the viewers of Malayalam news channels during the 2011 Kerala Assembly election.

Malayalam news channels much like their counterparts elsewhere bring about a substantial shift in the content of their newscasts and debate shows during election times. Compared to non-election period, the news channels during the campaign period would primarily focus on election topics, campaign issues and controversies, party manifestoes, key contestants, and other matters relating the electoral process such as election schedule, nomination process, and code of conduct to be followed.

Hence, in the context of the study objectives, the news and debate shows of Malayalam television news channels telecast during the campaign period which were wholly election-centric were reckoned as the cause or the intervention, and the changes in the credibility perceptions of television news and debates were treated as the effect. The most suitable research design for assessing the cause and effect relationship is the before-and-after design (Bartels, 1997; Johnston, Blais, Brady, \& Crete, 1992, Kumar, 2005).

The before-and-after design demands that data on the variables is collected from the viewers twice, before and after the introduction of treatment factor. In addition, the design also called for the constitution of a panel of respondents drawn from the population. Constitution of a panel enhances the reliability of before and after comparisons as the same individuals would be responding to questions at both times. In recognition of these advantages, a panel of respondents was constituted from among those who were registered voters in Kerala and were viewers of the prime time news and debate shows of four popular Malayalam news channels: News Hour show of Aisanet; News Night show of Indiavision; News N Views programme of People TV; and Manorama news channel's programme titled Counter Point and Prime-Time News.

\section{III.1. Sample Selection and Constitution of Panel}

Keeping in view the time and resource constraints, a purposive sample of 540 individuals was drawn through a multistage procedure. First, the state of Kerala which is located in the South western part of India was divided into three zones, North, Central and South. From each zone, one Assembly constituency was purposively selected based on its voting pattern. In Kerala, a large number of constituencies have certain fixed voting preferences. While some are consistent in electing the candidates of the Left Democratic Front (LDF) led by the Communist Party of India - Marxist (CPI-M), some other constituencies have always preferred the 
candidates of the United Democratic Front (UDF) led by the Indian National Congress (INC). There are quite a few floating constituencies whose preferences fluctuate between the two Fronts. Most often, these constituencies vote against the incumbent Front. Based on this criterion, Thalassery constituency which has returned LDF candidates since 1982 was chosen to represent the North zone. Representing the Central zone was the Puthuppally constituency which has consistently returned Indian National Congress candidates since 1970. From the South zone, the floating constituency of Chathannoor which fluctuates in its vote choice was selected.

From each constituency, one panchayath was randomly chosen. From each panchayath, three wards were chosen - one with UDF leaning, one with LDF leaning, and one floating. From each ward, a sample of 60 voters was drawn. At this stage, trained investigators went round the selected wards, identified and met the head of the households and selected one member from each household for inclusion in the sample. Here, care was taken to include only the registered voters who were also in the habit of watching news and debate shows telecast by Malayalam channels. Care was also taken to include in the sample individuals belonging to various socio-economic categories. Through this process, a sample 540 was drawn to serve as the panel.

Trained investigators collected the data from the panel members using structured questionnaires in two phases keeping in view the poll schedule announced by Election Commission of India on March 19 marking the beginning of the poll process. The campaigns were slated to end on April 11 and the voting was to take place on April 13, 2011. Thus, Phase-I data, which pertained to the period before the launch of the campaigns for the 2011 Kerala Assembly election, was collected on March on 19-20, 2011.The Phase-I questionnaire collected data pertaining to viewer's socio-demographic variables, their viewing habits of viewing prime time news and debates of four Malayalam news channels, and the perceived credibility of these programmes. Upon verification of the questionnaires, it was found that 10 respondents had not provided answers as per the instructions. Therefore, those 10 respondents were removed from the sample. As a result, the sample size got reduced to 530 .

The phase-II data was collected on April 11 and 12, 2011 as the campaigns had ended on April 11 and voting was scheduled for April 13, 2011. The phase-II questionnaire collected data on respondent's views and credibility assessment of news and debate shows telecast by Malayalam news channels during the campaign period. In this phase, 10 respondents could not be contacted despite repeated efforts. Another 8 respondents had left some questions unanswered or had not responded as per the instructions. With the exclusion of such questionnaires, the effective sample size of the panel got reduced to 512. Their responses were coded and analysed using SPSS Version 17.

\section{III.2. Credibility Measure}

As detailed in the earlier unit, credibility is a multidimensional concept. Meyer (1988) who zeroed on a set of five components representing media credibility has however noted that newspaper's credibility and believability may be the same dimensions. Bucy (2003, p 249) has pointed out that credibility is "most consistently operationalised as believability." As a result, media organizations such as Pew Research Centre consider credibility as a single construct and periodically assess media credibility through a four-point believability scale which ranges from believe 'all or most' to believe 'almost nothing'. Following this practice, this study used a three-point credibility scale ranging from ' highly credible' to 'somewhat credible and 'not at all credible' to assess the credibility of news and debate shows of the four Malayalam news channels before and during the 2011 Kerala Assembly election campaigns. The three-points were given a score of 3, 2, and 1 respectively. A comparison of the mean credibility scores before and after the campaign period would reveal the influence of the treatment factor - televised news and debates on poll issues during the campaign period - on the credibility perceptions of the voters.

\section{Analysis and Results}

Before analyzing the credibility aspects of news and debate shows of four Malayalam news channels, it was essential to ascertain their viewership. A widespread viewership would contribute to the validity of viewers' of credibility assessment. The analysis revealed that the viewers were attending to the four channels in varying manner. As reported in Table 1, Asianet News' News Hour had the highest viewership. It was being watched by 77 percent of the respondents of the study. The second most popular news and debate show was Counter Point debate show/Prime Time news of Manorama News channel. It was being watched by 66 percent of the respondents. India vision's News Night was the third most watched show. The least viewership (27.2 percent) was that of People TV's News N Views telecasts. 
Table 1: Most Often Watched News and Debate Shows on Malayalam TV Channels

\begin{tabular}{|l|c|}
\hline \multicolumn{1}{|c|}{ News and Debate Shows of Channels } & \multicolumn{1}{c|}{ (N=512) } \\
\hline $\begin{array}{l}\text { Asianet News' } \\
\text { News Hour }\end{array}$ & 77.0 \\
\hline $\begin{array}{l}\text { Manorama News' } \\
\text { Counter Point/Prime Time News }\end{array}$ & 66.6 \\
\hline $\begin{array}{l}\text { Indiavision's } \\
\text { News Night }\end{array}$ & 50.6 \\
\hline $\begin{array}{l}\text { People TV's } \\
\text { News N Views }\end{array}$ & 27.7 \\
\hline
\end{tabular}

Note: This was a multiple-choice question.

\section{IV.1. Credibility of News and Debate Shows Before and During the Campaign Period}

In respect of the first objective, first a look at the frequency data pertaining to the credibility measured before and during the campaign period using a three-point measure. The data presented in Table 2 clearly shows that in both the time periods an overwhelming majority of respondents perceived TV news and debate shows as 'somewhat credible' as against a small minority who rated the shows as 'highly credible' and 'not at all credible'. The data also indicates to an increase in the proportion of those perceiving the shows as 'highly credible' during the campaign and a commensurate decrease in the proportions of those rating news and debate shows as 'somewhat credible' and 'not at all credible'. Such a change indicates to a slightly higher assessment of credibility of news and debate shows by the respondents during the campaign period.

Table 2: Credibility of TV News and Debates before and during Campaigns: Frequency Data

\begin{tabular}{|c|c|c|c|c|}
\hline \multicolumn{5}{|c|}{ Credibility of News and Debate Shows } \\
\hline \multirow{2}{*}{$\begin{array}{l}\text { Credibility } \\
\text { Levels }\end{array}$} & \multicolumn{2}{|c|}{ Before Campaigns } & \multicolumn{2}{|c|}{ During Campaigns } \\
\hline & $\mathrm{N}$ & $\%$ & $\mathrm{~N}$ & $\%$ \\
\hline Highly credible & 33 & 6.4 & 58 & 11.3 \\
\hline Somewhat credible & 444 & 86.7 & 427 & 83.4 \\
\hline Not at all credible & 35 & 6.8 & 27 & 5.3 \\
\hline Total & 512 & 100.0 & 512 & 100.0 \\
\hline
\end{tabular}

And to test the statistical significance of differences in credibility before and during the campaign period, the interval data was subjected to paired $t$-test. The results reported in Table 3 show a mean credibility score of 1.9961 before the launch of election campaigns and a slightly higher mean credibility score of 2.0605 when the news and debate shows of Malayalam news channels had become election-centric. The increase in mean credibility, though not substantial, was statistically significant as borne out by t-test at .003 significance level.

Table 3: Credibility of TV News and Debates before and during Poll Campaigns

\begin{tabular}{|c|c|c|c|c|c|c|c|c|c|}
\hline \multirow[t]{2}{*}{ Pairs } & \multicolumn{3}{|c|}{$\begin{array}{l}\text { Paired sample } \\
\text { Statistics }\end{array}$} & \multicolumn{3}{|c|}{$\begin{array}{c}\text { Paired Differences } \\
\text { (Credibility before and during } \\
\text { the campaign) }\end{array}$} & \multicolumn{3}{|c|}{ Paired $t$-test Results } \\
\hline & $\mathbf{N}$ & Mean & $\begin{array}{l}\text { Std } \\
\text { Dev }\end{array}$ & Mean & Std Dev & $\begin{array}{l}\text { Std } \\
\text { Error of } \\
\text { Mean } \\
\end{array}$ & $t$ & df & $\begin{array}{c}\text { Sig } \\
\text { (2 tailed) }\end{array}$ \\
\hline $\begin{array}{l}\text { Before } \\
\text { Campaign }\end{array}$ & 512 & 1.9961 & 36477 & -.06445 & .49434 & .02185 & -2.950 & 511 & .003 \\
\hline $\begin{array}{l}\text { During } \\
\text { Campaign }\end{array}$ & 512 & 2.0605 & .40332 & & & & & & \\
\hline
\end{tabular}

Based on this result, two interrelated deductions can be drawn. First, media credibility doesn't remain constant across time. Instead, it undergoes change when media focus their attention on major events such as elections that are of great importance in democracies. Second, an increase in the mean credibility score of news and debate shows telecast during the campaigns indicates that the content of these programmes was considered by the viewers as important in understanding the election scenario. And perhaps therefore they attached a higher credibility to election-centric news and debate shows of television news channels.

\section{IV.2 Credibility of Poll News and Debates by Socio-Demographic Variables}

The second objective was to examine whether the credibility of news and debate shows telecast during election campaigns is independent of voters' socio-demographic variables. To realise this objective, respondents' credibility assessments of news and debate shows during the campaign period were subjected to $t$-test in respect of the gender variable which had two groups, and Analysis of Variance (ANOVA) in respect of other socio- 
demographic variables where each variable had more than two groups. The results are reported in Table 4. The results, show that between the two gender groups, male viewers' credibility mean of 2.0609 was only fractionally higher than that of the female viewers' credibility mean of 2.0600 . This abysmally low difference between the means of the two gender groups was not of any statistical significance as shown by the $t$-test. Thus, the deduction is that male and female did not differ in their credibility perceptions of news and debate shows telecast on Malayalam TV channels during the campaigns.

Table 4: Credibility of TV News and Debate Shows during Campaign by Socio-Demographic Variables

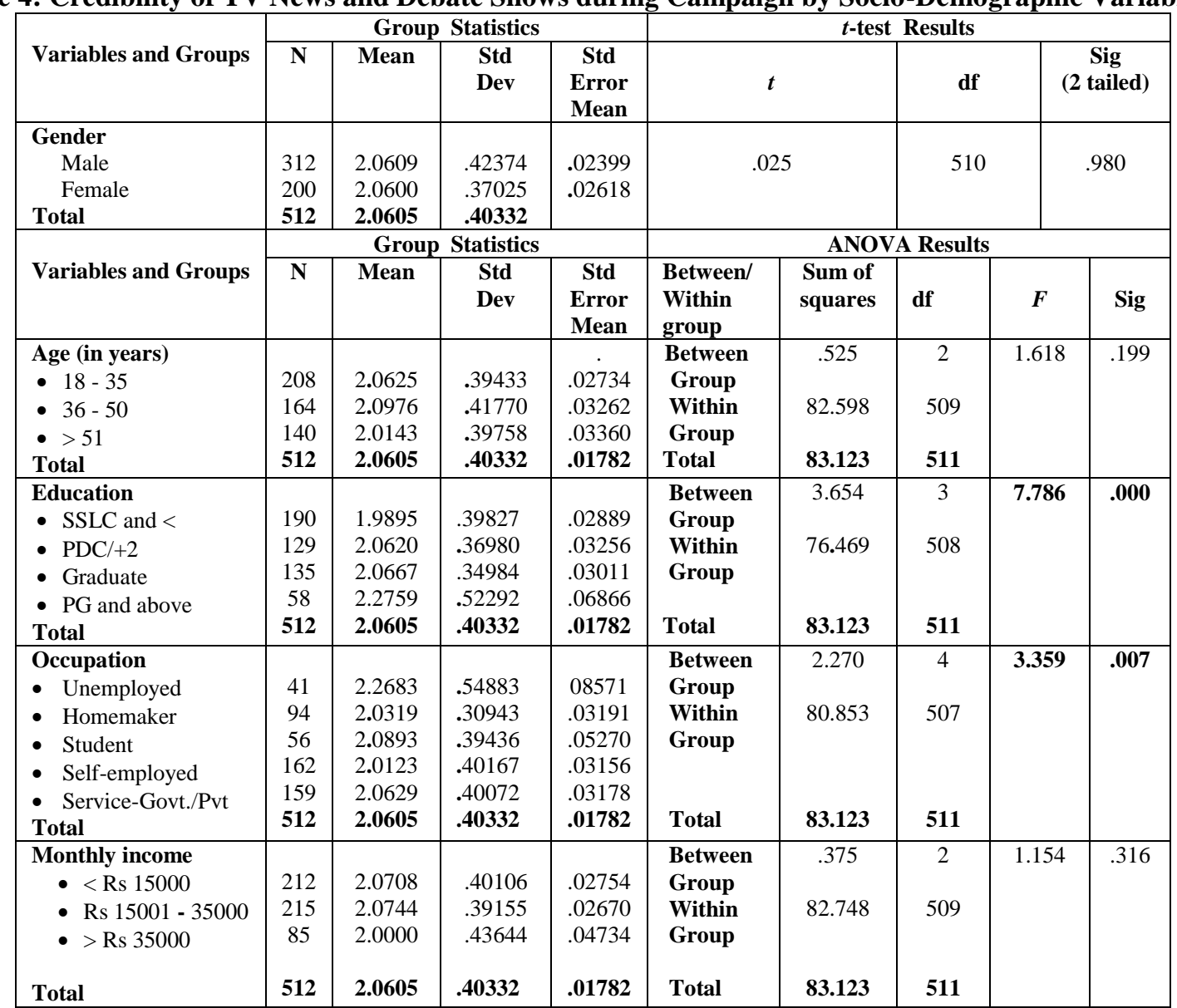

Likewise, the analysis of variance also showed that the differences in the credibility perceptions of poll news and debates were not statistically significant among respondents belonging to various age and income categories.

However, educational attainment and occupation of the respondents was found to have a statistically significant bearing on the credibility perceptions of election-centric news and debate shows telecast during the campaigns. Those with the highest attainment of postgraduate education and above had the highest mean credibility of 2.2759 followed by the graduates (2.0667) and those with PDC/+2 education (2.0620) in that order. Those with the lowest education attainment of SSLC and below had attributed the lowest credibility (1.9895) among the four educational groups. Among the occupation groups, the credibility of news and debate shows during the campaign period was the highest among the unemployed in relation to others.

From these results, it emerges that credibility perceptions of poll news and debates were independent of gender, age and occupation variables. The other two variables of education and occupation had a bearing on the credibility assessment of election-centric news and debate shows. In that those with higher educational attainment and the unemployed attached a significantly higher credibility than other.

\section{Conclusion}

A comparison of the credibility of news and debate shows of Malayalam news channels assessed before and during the election campaigns yielded potent results. First, the results confirm that media credibility is situational. It undergoes change when mass media units such as television news channels exhaustively report and debate major events such as elections to governing bodies like the parliament and state legislatures. The change 
in credibility of the media could be in the positive or negative directions. A positive change as detected in this study which showed a higher mean credibility score of news and debate shows telecast during election campaign period, unambiguously indicates that audience value news channels' telecasts during election times.

Yet another conclusion is that the tendency of attaching a higher credibility to election campaign's news and debates on television will not be dependent on the gender, age and economic status of the audience. However, the educational attainment and occupation of the viewers matter. The highly educated and the unemployed tend to attach a higher credibility to election-centric news and debate programmes than those with lower education and the employed.

These results need be confirmed through similar studies in different socio-political settings. Perhaps, a similar study could be conducted during the $14^{\text {th }}$ Kerala Legislative Assembly election and elections to the legislative assemblies of other Indian states in the coming years. Such efforts besides enriching the field of credibility research may also make Indian media organisations realize the importance of credibility of their news and debate progarmmes.

\section{References}

[1]. P.F. Lazarsfeld, B. Berelson, \& H. Gaudet, The people's choice: How the voter makes up his mind in a presidential campaign (New York: Duell Sloan, 1944).

[2]. S. Kraus, \& D. Davis, The effects of mass communication on political behaviour (London: The Pennsylvania State University Press, 1976)

[3]. W. Wanta, and Y.W. Hu, The effects of credibility, reliance and exposure on media agenda setting: A path analysis model, Journalism \& Mass Communication Quarterly, 71, (1), 1994, 90 - 98.

[4]. G.J. O'Keefe, Persuasion: Theory and research (Newbury, CA: Sage, 1990)

[5]. C.C. Bracken, Perceived source credibility of local television news: The Impact of television form and presence, Journal of Broadcasting \& Electronic Media, 50:4, 2006, 723-741.

[6]. F.S. Haiman, An experimental study of the effects of ethos in public speaking (Evanston, Ill: Northwestern University, 1948)

[7]. C.I. Hovland, I.L. Janis, \& H.H. Kelley, Communication and persuasion (New Haven: Yale University Press, 1953)

[8]. L. Sargent, The dimension of source credibility, Journalism Quarterly, 42, 1965, 35-42.

[9]. [J. Newhagen, and C. Nass, Differential criteria for evaluating credibility of newspapers and TV news, Journalism quarterly, 66(2),1989, 277-284.

[10]. C. Gaziano, \& K. McGrath, Measuring the concept of credibility, Journalism Quarterly, 63, 1986, 451-462.

[11]. P. Meyer, Defining and measuring credibility of newspapers: Developing an index, Journalism Quarterly, 65, 1988, 567-574.

[12]. T.J. Johnson, \& B.K. Kaye, Cruising is believing? Comparing Internet and traditional sources on media credibility measures, Journalism and Mass Communication Quarterly, 75, 1998, 325-340.

[13]. T.J. Johnson, \& B.K. Kaye, Using is believing: The influence of reliance on the credibility of online political information among politically interested Internet users, Journalism and Mass Communication Quarterly, 77 (4), 2000, 865-879.

[14]. E. Bucy, Media credibility reconsidered: Synergy effect between on-air and online news, Journalism and Mass Communication Quarterly, 88-2, 2003, 247 - 264.

[15]. T. Rimmer, \& D. Weaver, Different questions, different answers? Media use and media credibility', Journalism quarterly, 64(1) 1987, 8-36.

[16]. W.R. Severin, \& J. W. Tankard, Communication theories origins, methods, and uses in the mass media (New York: Longman, 2001)

[17]. S. Kiouis, Public trust or mistrust? Perception of media credibility in the information age, Mass communication and society, 4(4), 2001, 381-403.

[18]. T.J. Johnson, \& B.K. Kaye, Webelievability: A path model examining how convenience and reliance predict online credibility, Journalism \& Mass Communication Quarterly. 79 (3), 2002, 619-642.

[19]. H. Lu, and J. E. Andrews, College students' perception of the absolute media credibility about SARS-related news during the SARS outbreak in Taiwan, China Media Research, 2(2), 2006, 85-93.

[20]. W. Schweiger, Media credibility - experience or image?: A survey on the credibility of the World Wide Web in Germany in comparison to other media, European Journal of Communication, 51 (1), 2000, 37 - 59.

[21]. D. L. Geary, The decline of media credibility and its impact on public relations, Public Relations Quarterly, 50(3), 2005, 8-12.

[22]. D.K. Berlo, J.B. Lemert, and R.J. Mertz, Dimensions for evaluating the acceptability of message sources, Public Opinion Quarterly, $33(4), 1969,563-576$.

[23]. S.H. Chaffee, Massmedia and interpersonal channels: Competitive,convergent, or complementary? in G. Gumpert, \& R. Cathcart (Eds.), InterMedia: Interpersonal communication in a media world (New York, N.Y.: Oxford University Press, 1982) 57-77.

[24]. B.W. Roper, Emerging profile of television and other mass media: Public attitudes, 1959-1967 (New York: Television Information Office, 1967).

[25]. H. Erskine, The polls: Opinion of the news media, Public Opinion Quarterly, 34 (4), 1970, 630- 643.

[26]. Pew Research Centre for the People \& the Press, News media's improved image proves short-Lived', 2002, http://www.peoplepress.org/2002/08/04/ retrieved on Sept 13, 2012.

[27]. C. Doherty, The public isn't buying press credibility, 2005, http://www.nieman. harvard.edu, Retrieved on Sept 3, 2011.

[28]. H. Thomson, Trust in the Media, 2011, http://yougov.co.uk Retrieved on Dec 12, 2011.

[29]. B.I. Nacos, Y. Bloach-Elkon, and R.Y. Shapiro, Post-9.11 terrorism threats and public perception in the United states, International Journalism of Conflict and Violence, 1 (20), 2007, 105 - 126.

[30]. Pew Research Centre for the People \& the Press, News media's improved image proves short-Lived, 2002, http://www.peoplepress.org/2002/08/04/ retrieved on Sept 13, 2012.

[31]. R. Mulder, A log-linear analysis of media credibility. Journalism Quarterly, 58, 1981, 635 - 638.

[32]. M.J. Robinson, \& A. Kohut, Believability and the press, Public Opinion Quarterly, 52, 1988, 174 - 189.

[33]. M. Ibelema, \& L. Powell, Cable television news viewed as most credible, Newspaper Research Journal, 22 (1), 2001, 41 - 51.

[34]. C.E. Beaudoin, \& E. Thorson, Credibility perception of news coverage of ethnic Groups: The predictive use of race and ethnic groups, Howard Journal of Communication, 16 (1), 2005, 33 - 48. 
[35]. L.M. Bartels, Three virtues of panel data for the analysis of campaign effects, Paper presented at the conference on campaign effects, Vancouver, British Columbia, 1997.

[36]. R. Johnston, A. Blais, H. Brady, J. Crete, Letting the people decide: Dynamics of a Canadian election (Kingston: McGill-Queen's University Press, 1992).

[37]. R. Kumar, Research Methodology: A step-by-step guide for beginners (New Delhi: Pearson Education Australia, 2005). 